\title{
FERDINAND ALQUIÉ CONTRA O MONISMO DE ESPINOSA
}

\author{
Marcio Francisco Teixeira de Oliveira ${ }^{1}$ \\ Universidade do Estado do Rio de Janeiro (UERJ) \\ (D) https://orcid.org/0000-0001-6346-023X \\ E-mail: franciscomarciorj@gmail.com
}

\section{RESUMO:}

Este artigo tem como objetivo apresentar a rejeição de Ferdinand Alquié à tese do monismo de Espinosa. Diferentemente de Descartes, que sustenta o dualismo, a tese do monismo determina que só pode existir uma única substância constituída de infinitos atributos. Esta tese é fundamental para a consolidação de todo o sistema filosófico de Espinosa. Alquié conclui que a tese do monismo é incompatível com a estrutura argumentativa do primeiro livro da Ética. A abordagem de Alquié é importante porque expõe o problema de maneira muito clara, razão pela qual a apresentação de seu pensamento pode ser útil àqueles que se interessam pelos estudos da filosofia de Espinosa.

PALAVRAS-CHAVE: Espinosa; Alquié; Monismo; Substância; Atributo.

\section{FERDINAND ALQUIÉ AGAINST THE SPINOZA'S MONISM}

\begin{abstract}
:
This paper aims to present Ferdinand Alquié's rejection of Spinoza's monism. Unlike Descartes, who sustains dualism, the monist thesis determines that there can be only one substance constituted by infinite attributes. This thesis is fundamental for the consolidation of the entire philosophical system of Spinoza. Alquié concludes that the monist thesis is incompatible with the argumentative structure of the first book of the Ethics. Alquié's approach is important because it exposes the problem very clearly, which justifies the presentation of his thinking, that can be useful to those who are interested in the studies of Spinoza's philosophy.
\end{abstract}

KEYWORDS: Spinoza; Alquié; Monism; Substance; Attribute.

\footnotetext{
1 Doutorando em Filosofia na Universidade do Estado do Rio de Janeiro (UERJ), Rio de Janeiro - RJ, Brasil. Professor da Universidade do Estado do Rio de Janeiro (UERJ), Rio de Janeiro - RJ, Brasil.
}

OLIVEIRA, Marcio Francisco Teixeira de. Ferdinand Alquié contra o monismo de Espinosa. Griot : Revista de Filosofia, Amargosa - BA, v.18, n.2, p.72-85, dezembro, 2018. 
O monismo de Espinosa afirma que a realidade não pode ser fragmentada, que só pode existir uma única substância cuja unidade é garantida pela compatibilidade entre sua natureza única e absolutamente infinita e a multiplicidade real dos seus infinitos atributos, dos quais podemos conhecer o pensamento e a extensão. Por mais que Espinosa estivesse convicto de ter provado a coerência dessa unidade, existem opiniões divergentes a propósito da validade do monismo. Como veremos, o cartesiano Ferdinand Alquié, que abordou este tema em um curso chamado Nature et vérité dans la philosophie de Spinoza [Natureza e Verdade na filosofia de Espinosa] e também na obra Le rationalisme de Spinoza [O Racionalismo de Espinosa], é um dos principais intérpretes que pretendem invalidar o monismo. Essa abordagem é importante porque ele consegue expor o problema de maneira muito clara, razão pela qual a apresentação de seu pensamento pode ser muito útil àqueles que se interessam pela filosofia de Espinosa.

Para que seja possível compreender a questão que nos interessa, primeiramente apresentaremos dois conceitos centrais, os de substância e atributo, presentes nas definições, axiomas e proposições desenvolvidas na primeira parte da Ética e que conduzem à tese do monismo. Feito isso, veremos a argumentação erigida por Alquié contra a tese espinosista.

\section{Substância e atributo, conceitos centrais para a compreensão da filosofia de Espinosa}

Nas oito definições que inauguram a primeira parte da Ética, são apresentados conceitos indispensáveis para a compreensão dos três elementos ontológicos que constituem a realidade, isto é, Deus, os atributos e os modos. Podemos separar essas oito definições em três blocos: o primeiro, dedicado à Natureza, é constituído pelas definições que versam sobre a causa de si (Def. 1), sobre a substância (Def. 3), sobre Deus (Def. 6), sobre a coisa livre (primeira parte da Def. 7) e sobre a eternidade (Def. 8); o segundo bloco, referente aos atributos, é a própria definição de atributo (Def. 4); e o terceiro bloco, ao definir o conceito de finito (Def. 2), de modo (Def. 5) e de coisa coagida (segunda parte da Def. 7), trata dos modos.

Os axiomas dessa primeira parte da obra, que sucedem às definições, apresentam os princípios básicos para a explicação da existência e da causação dos entes. $O$ que explica a existência das coisas? De acordo com Espinosa, tudo o que existe precisa existir em si mesmo ou em outra coisa (Axioma 1), de tal modo que qualquer ente que não possa ser concebido por um objeto externo precisa ser concebido por si mesmo (Axioma 2). E, porque a compreensão da existência das coisas tem relação com a compreensão das suas causas, Espinosa formulou também axiomas sobre a causação: toda causa exige um efeito e toda ausência de causa inibe a existência de qualquer efeito (Axioma 3), mas é preciso que se conheça a causa para que o efeito possa ser compreendido corretamente (Axioma 4), além disso, não se pode tentar relacionar coisas que não tenham nenhuma relação conceitual, pois este procedimento inviabiliza o conhecimento da verdadeira ligação existente entre elas (Axioma 5). Em contrapartida, toda ideia verdadeira precisa ter, para que seja verdadeira, correspondência com o objeto pensado (Axioma 6), isto é, para que eu tenha uma ideia verdadeira sobre algo, este deverá necessariamente existir da

OLIVEIRA, Marcio Francisco Teixeira de. Ferdinand Alquié contra o monismo de Espinosa. Griot : Revista de 
maneira como é pensado, e se, por outro lado um objeto for concebido como inexistente, a essência deste objeto não poderá envolver a sua existência (Axioma 7).

A partir dessas definições e axiomas da primeira parte da Ética, Espinosa desenvolveu proposições sobre o que constitui, causa e mantém a existência da integralidade do real. Isso é, de Deus, ser imanente que é causa necessária de si e de todas as coisas presentes na natureza. O filósofo afirma que "Deus", "Natureza" e "Substância" são nomes equivalentes. Deus é a substância absolutamente infinita que pode ser conhecida como causa (Natureza Naturante) e como efeito (Natureza Naturada).

Dentre os três blocos de primeiras definições que abrem a Ética, daremos destaque à apresentação das definições que versam sobre a substância e o atributo, pois enquanto a substância e os atributos são a Natureza Naturante, os modos constituem a Natureza Naturada, não estando diretamente ligados à apresentação do problema do monismo.

3. Por substância compreendo aquilo que existe em si mesmo e por si mesmo é concebido, isto é, aquilo cujo conceito não exige o conceito de outra coisa do qual deva ser formado.

4. Por atributo compreendo aquilo que, de uma substância, o intelecto percebe como constituindo a sua essência. (SPINOZA, 2008, p.13).

Substância e atributo são conceitos chave para a apresentação do monismo. Estes conceitos são de origem aristotélica, tiveram influência nos estudos da escolástica e estão presentes na filosofia cartesiana. Apesar de não os ter inventado, Espinosa realizou uma reinterpretação destes conceitos para a realização de seu projeto filosófico.

\section{A substância}

A primeira definição da Ética apresenta o conceito de causa sui-ou "causa de si" $^{\prime \prime}$. A causa sui possibilita a existência e o conhecimento da substância, porque é a existência da causa e o conhecimento dela que permitem, respectivamente, a produção do efeito e o seu conhecimento. Para que um efeito exista e seja conhecido, a causa deverá, necessariamente, existir e ser conhecida ${ }^{3}$. Isso também pode ser visto no Breve tratado, onde o filósofo afirma que "se nos servirmos bem do nosso intelecto no conhecimento das coisas, devemos conhecê-las em suas causas. Ora, como Deus é a causa primeira de todas as outras coisas, o conhecimento de Deus é anterior ao conhecimento de todas as demais" (SPINOZA, 2012, p.103). Portanto, esta primeira definição é importante porque comunica a função ontológica e gnosiológica da causa (GUEROULT, 1968, p.41), definição esta que permitirá a demonstração da autossuficiência ontológica da substância, na EIP7, e a demonstração da existência de Deus, na EIP12.

\footnotetext{
2 "Por causa de si compreendo aquilo cuja essência envolve a existência, ou seja, aquilo cuja natureza não pode ser concebida senão como existente". EI, definição 1 .

${ }^{3}$ Para Espinosa, tudo requer uma causa, pois "se não existe nenhuma causa determinada, é impossível que se siga um efeito" (EI axioma 3), e "o conhecimento do efeito depende do conhecimento da causa e envolve este último" (EI axioma 4).
}

OLIVEIRA, Marcio Francisco Teixeira de. Ferdinand Alquié contra o monismo de Espinosa. Griot : Revista de Filosofia, Amargosa - BA, v.18, n.2, p.72-85, dezembro, 2018. 
Ao pensar a substância a partir do conceito de causa sui, Espinosa afastou-se da concepção tradicional, segundo a qual, de acordo com os escolásticos, por exemplo, os conceitos de substância e atributo seriam intrínsecos ao caráter predicativo do pensamento - às atribuições formuladas nos nossos juízos - já que por elas um indivíduo poderia identificar e distinguir na natureza, segundo as exigências do pensamento e da linguagem, os sujeitos e as qualidades desses sujeitos (ALQUIÉ, 2003, p.80). Seguindo o raciocínio de Brunschvicg, Alquié explica que a teoria da substância possui sua origem na estrutura linguística grega, segundo a qual o verbo "ser" desempenharia uma função essencial, onde os substantivos e adjetivos corresponderiam, respectivamente, à substância e aos atributos. Por exemplo, quando alguém afirma "o quadro é branco", "a porta é azul", "o computador é preto", a existência de duas realidades seria constatada: a primeira ("o quadro", "a porta" e "o computador") sendo concebida nela mesma como autossuficiente, ao menos em certo grau; e a segunda necessitando de um suporte para existir, pois não seria capaz de sustentar por si mesma sua própria existência. Isto acontece com as cores dos objetos anteriores, que só poderiam se manifestar neles, já que o "branco", o "azul" e o "preto" não poderiam existir fora de qualquer coisa branca, azul ou preta. A primeira realidade caracterizaria a substância e a segunda o atributo.

No pensamento escolástico, existem duas maneiras de compreender as qualidades de uma substância. As qualidades podem ser separáveis da substância (qualitates) ou inseparáveis da substância (atributa). A substância pode existir sem as diversas qualidades "separáveis", mas não sem as "atributivas". Ainda assim, o atributo não pode ser identificado com a própria substância, porque apenas designa dentre as qualidades substanciais aquelas que lhe são essenciais. Cabe assinalar que o que Espinosa quer designar como "atributo" não tem nenhuma ligação com a característica atributiva reconhecida pela escolástica, pois, para ele, o atributo não qualifica a substância, mas expressa a sua essência.

Descartes também pensou o conceito de substância. Ele anuncia na definição VII das Segundas Respostas que Deus é a única substância soberanamente perfeita, que teria produzido uma multiplicidade de substâncias de apenas dois tipos: as extensas e as pensantes, que dizem respeito aos dois atributos essenciais. Desta maneira, a metafísica cartesiana pressupõe a existência de substancias materiais e espirituais finitas e a existência de uma substância imaterial infinita, de tal modo que o nome "substância" pode ser atribuído a Deus e às diversas substâncias finitas que ocupariam o real na extensão tridimensional (as substâncias materiais ou corporais) e no pensamento (as substâncias imateriais).

A análise que Espinosa empreendeu sobre a definição cartesiana de substância foi importante para a elaboração do seu monismo, pois Descartes, ainda que mantivesse alguma proximidade com a visão escolástica, desenvolveu uma visão racionalista sobre o conceito. De acordo com Alquié (2003), no que diz respeito ao conceito de substância, Descartes, quando comparado aos pensadores da tradição escolástica, seria uma fonte mais direta, embora ainda vacilante, para Espinosa.

Ao definir o conceito de substância ao longo de suas obras, Descartes demonstra ambiguidade. Na definição V da exposição geométrica das Segundas Respostas, ele afirmou que a substância é "toda coisa em que reside imediatamente como em seu sujeito, ou pela qual existe, algo que concebemos, isto é, qualquer

OLIVEIRA, Marcio Francisco Teixeira de. Ferdinand Alquié contra o monismo de Espinosa. Griot : Revista de 
propriedade, qualidade, ou atributo, de que temos em nós real ideia" (DESCARTES, 1973, p.180); resulta desta definição que é a substância que possibilitaria a existência de tudo o que podemos conceber, posto que, se "o nada não pode ter nenhuma propriedade", como diria o próprio Descartes, a existência de qualquer propriedade exige um ser que sustente a sua realidade, requer "uma matéria metafísica" (DESCARTES, 1852, p.126), isto é, a substância. Portanto, para Descartes, o corpo e a alma não seriam a "pura extensão" ou o "puro pensamento", mas a coisa extensa (res extensa) e a coisa pensante (res cogitans), havendo sempre uma preeminência da substância com relação aos atributos; neste sentido, a substância cartesiana responderia a uma exigência ontológica, tal como a da tradição.

E a substância cartesiana poderia ser referida à "distinção dos pensamentos", que evidencia um aspecto diferente do raciocínio instaurado pela exigência ontológica. Descartes pretende combater o que ele julga ser um erro da filosofia medieval, qual seja o da confusão que provém da atribuição de características corporais às almas (e vice-versa): por exemplo, as afirmações "a alma se moveu" ou "o corpo estava quente" são indevidas, pois o calor é próprio da alma e não do corpo, já que depende de uma sensação percebida de maneira única pelo indivíduo, e, por outro lado, o movimento, porque envolve a noção de espaço, só pode ser atribuído ao corpo e não à alma ${ }^{4}$. Acontece, no entanto, que nós podemos afirmar na hora do banho, por exemplo, que "a água está quente"; o que queremos expressar com isso? Que a água, ela mesma, está sentindo a sua quentura? Claro que não, pois a água não pensa. De acordo com Descartes, nós devemos considerar que todas as coisas que existem ou são corpos ou são almas, é o que pode ser notado quando o filósofo afirma no parágrafo 53 da primeira parte dos Princípios da Filosofia que tudo o que podemos atribuir aos corpos pressupõe a extensão e depende daquilo que é extenso e, do mesmo modo, todas as propriedades que nós encontramos na coisa que pensa são apenas modos diferentes de pensar. Ou seja, os atributos essenciais seriam indispensáveis para que se distingam os dois tipos de substância. Neste ponto, Descartes teria substituído a noção de substância como "sujeito ontológico" pela noção de "sujeito lógico", que suportaria a distinção que o meu pensamento pode realizar a fim de distinguir clara e distintamente os elementos que constituem o real. Enquanto sujeito ontológico haveria distinção real entre atributo e substância, mas enquanto sujeito lógico esta distinção não passaria de uma distinção de razão ${ }^{5}$.

Do exposto, Alquié conclui que a teoria cartesiana da substância mantém, contraditoriamente, uma dupla inspiração: uma inspiração ontológico-escolástica que busca, sob os atributos, conhecer a substância, o sujeito ontológico; e outra inspiração racionalista-científica que confunde a substância com o seu atributo essencial, ao afirmar que "a alma é o pensamento" e "o corpo é a pura extensão". Neste caso, o atributo não é o ser da substância, mas a sua natureza. Descartes opera uma substantificação no interior de cada atributo essencial.

E Espinosa privilegia o tema da causalidade ao pensar a substância. A definição que abre a Ética, sobre a causa sui, destaca a importância que a

\footnotetext{
4 Para Descartes, justamente porque as almas vegetativa e motriz - pertencentes à filosofia medieval necessitariam do conceito de corporeidade, elas não poderiam existir. Descartes admite que a alma só pode ser um puro pensamento.

${ }^{5}$ Isto é, aquela que acontece apenas na mente como resultado de uma abstração do real.
}

OLIVEIRA, Marcio Francisco Teixeira de. Ferdinand Alquié contra o monismo de Espinosa. Griot : Revista de Filosofia, Amargosa - BA, v.18, n.2, p.72-85, dezembro, 2018. 
causalidade ocupa na obra. A origem desta definição é cartesiana, surge da contrariedade de Descartes à crença escolástica de que toda causa é anterior ao seu efeito, pois "do ponto de vista tomista, não se pode admitir que um ser seja causa de si: um tal ser deveria existir antes de existir, e isso é um absurdo" (ALQUIÉ, 1998, p.127). Para a tradição escolástica (GLEIZER, 2014, p.33) "ser por si" significa "não ter causa", mas no caso de Descartes, na medida em que ele defende o caráter universal do princípio de causalidade, Deus deve ser entendido como um "ser por si como por uma causa", o filósofo estabelece uma analogia entre a causa formal e a causa eficiente, pois Deus "faz de alguma maneira em relação a si mesmo o que a causa eficiente faz em relação ao seu efeito (DESCARTES, AT-IX,88). De acordo com Descartes, Deus é causa de si e causa do mundo, mas o argumento ontológico que demonstra a necessidade da existência de Deus estaria apenas ligado a Deus e não ao mundo. Espinosa, por sua vez, entende que Deus, por um mesmo ato, é causa do mundo e causa de si. Sendo assim, Deus é causa imanente do mundo que ele é. É importante assinalar que o termo "causa de si" não diz respeito a uma causa que antecede um efeito, não há relação externa e nem cronológica, visto que a causa que está aqui tomada num sentido matemático, racionalista - é contemporânea ao seu efeito.

\section{O atributo}

Outro elemento fundamental para a compreensão do problema do monismo é o conceito de atributo, que é o "princípio ontológico da substância, pois é constitutivo da sua realidade; e princípio de inteligibilidade da substância, posto que ele proporciona seu verdadeiro conhecimento" (GUEROULT, 1968, p.47). Para Gueroult, enquanto a definição de substância espinosista enuncia o critério da substancialidade em geral (com a definição de substância como aquilo que é em si e concebido por si), o atributo aponta para a essência pela qual uma coisa pode efetivamente ser uma substância e ser concebida como tal pelo entendimento, essência que só pode ser percebida pelo entendimento puro na medida em que as ideias são adequadas, e, por isso, idênticas no indivíduo e em Deus - que, além de ter nele mesmo as ideias verdadeiras de todas as coisas que formam o seu ser, a saber, o pensamento, a extensão e todos os infinitos atributos, tem ainda a ideia verdadeira dele próprio como sendo constituído por estes atributos.

Diferentemente de como sugeriu a tradição precedente a Espinosa, entre o atributo e a substância há apenas uma distinção de razão. Com a demonstração da Proposição 10 da primeira parte da Ética, Espinosa afirma que "o atributo deve ser concebido por si mesmo"; se, pela definição 3, aquilo que é concebido por si é em si, então o atributo tem de ser a substância. Isso é confirmado pelo que Espinosa propõe na demonstração da EIP4, quando ele diz que "não existe nada, pois, fora do intelecto pelo qual se possam distinguir várias coisas entre si, a não ser as substâncias ou, o que é o mesmo (pela def. 4), seus atributos e suas afeções", de tal modo que a conclusão de que o atributo só pode ser uma substância torna-se irrenunciável. Vê-se com isso que o atributo não pode ser - como sustentava a tradição escolástica - um simples predicado, um adjetivo incapaz de sustentar a essência pela qual Deus seria Deus, mas só pode ser um substantivo.

OLIVEIRA, Marcio Francisco Teixeira de. Ferdinand Alquié contra o monismo de Espinosa. Griot : Revista de 
Ao identificar a substância ao seu atributo essencial, Espinosa procurou inviabilizar a definição tradicional de substância como sujeito de inerência, cujos predicados seriam os únicos acessíveis ao entendimento; ele fez isso ao defender, contra o pensamento da Escola, que as definições de substância e atributo não devem apontar para duas entidades diferentes, mas para dois aspectos de um mesmo ser, onde temos, por um lado, a natureza constitutiva, a realidade desse ser - que é o atributo e aquilo que ele revela - e, por outro lado, sua inseidade e sua autossuficiência - que são os critérios necessários para afirmar a substancialidade. Desta forma, Espinosa acreditou que a natureza da substância poderia ser inteiramente conhecida, já que haveria identidade entre o atributo e a substância.

Quando comparados à tradição, percebemos que os termos "atributo" e "substância" ganharam uma nova significação ao longo das obras de Espinosa. A "substância" (GUEROULT, 1968, pp. 55-56) é um conceito que, para Descartes e para a Escola, não tinha um sentido unívoco, porquanto poderia se aplicar tanto às coisas como a Deus; a este porque não precisaria de nada para existir, e àquelas porque não dependeriam da existência de outras coisas, mas apenas de Deus, para sustentar suas existências. Espinosa, por outro lado, procurou defender a univocidade da substância ao entender o conceito de substância como sendo em si e concebida por si.

Contudo, tal univocidade não seria mantida - como poderiam alegar alguns críticos de Espinosa - se ele passasse a denominar "substância" as coisas individuais de único atributo ao mesmo tempo que aquela constituída de uma infinidade de atributos (como acontece nas proposições inicias da Ética, por exemplo). Para resolver este problema, Gueroult afirma que Espinosa teria usado dois processos diferentes: $1^{\circ}$ - na Carta IX à Simon de Vries, o holandês designou como substâncias as coisas que seriam constituídas de um único atributo, e como Ser a coisa constituída de uma infinidade de atributos (Deus); $2^{\circ}$ - Na Ética, o termo em questão é utilizado provisoriamente para fazer referência às coisas de único atributo, para depois, e definitivamente, designar Deus como substância única e infinitamente infinita.

Além da substância, o atributo, "que nada mais é do que aquilo que revela e constitui o ser de uma substância" (GUEROULT, 1968, p.56), que também participaria da univocidade da substância, foi um conceito transformado pelo esforço intelectual de Espinosa, já que, enquanto Descartes considerava como atributos as perfeições ou qualidades de Deus (causa sui, independência, imutabilidade, eternidade, etc.), os modos ou qualidades invariáveis (a duração e a existência, na coisa; o tempo, os números e os universais, no pensamento), e o atributo principal ("que constitui e faz conhecer a natureza de uma substância"), Espinosa preservou apenas este último sentido, conservando as principais características que o atributo principal cartesiano envolvia, para concluir que: a) cada atributo pode ser clara e distintamente conhecido, porque cada um "é concebido por si mesmo, independentemente de qualquer outro" (EIIIP6); b) o atributo constitui a essência da substância e se reciproca com ela, distinguindo-se dela apenas por uma distinção de razão; e c) ele revela a substância tal como ela é em si, não apenas nos limites do finito, tornando-a absolutamente inteligível.

OLIVEIRA, Marcio Francisco Teixeira de. Ferdinand Alquié contra o monismo de Espinosa. Griot : Revista de 


\section{O problema do monismo a partir de Ferdinand Alquié}

"Se Deus é o mesmo que seus atributos, por que esta separação?", ou haveria, realmente, alguma distinção entre eles? Este é o questionamento que abre a sequência de páginas dedicadas à análise do problema do monismo pelo comentador Ferdinand Alquié no curso Natureza e verdade na filosofia de Espinosa. Apesar de Espinosa defender a unidade da substância com relação aos atributos, ao entender que estes são constitutivos da sua essência, o comentador inquire se é verdadeiramente possível pensar esta unidade. Ao se deparar com a identificação que Espinosa estabelece entre a multiplicidade de atributos e a substância única, ele levanta a possibilidade de haver incoerência na argumentação do holandês: como, ao mesmo tempo, o atributo - que é a substância - pode ser substância una e expressão múltipla? Como conciliar, ele questiona, a "doutrina do atributo substância" (que garante a unidade) e a do "atributo expressão" (pela qual a substância poderia ser expressa por uma infinidade de atributos que constituiriam o seu ser e permitiriam o seu conhecimento)?

Alquié apresenta três hipóteses que tentam explicar esta unidade e responder suas inquietações. Como veremos, após apresentarmos duas hipóteses que não foram propostas pelo próprio comentador, ele reconhecerá na sua própria hipótese que o problema do monismo não garante uma solução que mantenha a coerência interna da obra do holandês, pois haveria uma superioridade da substância em relação aos seus atributos.

A primeira hipótese analisada, proposta por Erdmann, coloca em destaque a questão do entendimento. Erdmann, ao se deparar com a definição 4 da primeira parte da Ética - na qual o atributo é definido como o que o intelecto percebe de uma substância como constitutivo de sua essência -, teria afirmado que a distinção de atributos seria fruto da postura analítica, do caráter divisor que é próprio do entendimento, que, por ser incapaz de compreender a unidade da substância em sua intimidade concreta e última, faria a distinção atributiva - como uma distinção subjetiva e não real - e constituiria as essências destes atributos (ALQUIÉ, 2003, p.95). Alquié afirma que Erdmann se deixou contaminar pela filosofia kantiana, ao ter admitido que a essência do atributo seria posta pelo entendimento e, por isso, considera esta hipótese impossível. Para justificar a incoerência da hipótese, Alquié sustenta que Erdmann, ao valorizar o intelecto, parece ter esquecido que o intelecto é apenas um modo do atributo pensamento, ou seja, o intelecto não pode originar os atributos. Alquié lembra que na demonstração da proposição 4 da primeira parte da Ética Espinosa já demonstrara que os atributos existem fora do entendimento, por isso não podem ser concebidos como frutos do entendimento humano. Desta maneira, prova-se que o próprio Espinosa já tinha invalidado esta hipótese ao impossibilitar a crença de que os atributos possam ser frutos da ação do entendimento (que nada mais é do que um modo).

A segunda hipótese pertence a Brunschvicg. Este, segundo Alquié, compreende que o termo "substância única" seja a mesma coisa que "inteligibilidade universal" e esteja diretamente ligado ao princípio de identidade. Para Brunschvicg, o princípio de identidade das ordens causais da substância seria sustentado pela sua inteligibilidade: na substância há algo de idêntico entre todos os atributos, a saber, a

OLIVEIRA, Marcio Francisco Teixeira de. Ferdinand Alquié contra o monismo de Espinosa. Griot : Revista de 
capacidade que eles possuem de produzir os modos que estão neles, e esta identidade não dependeria da natureza do atributo, que é causa dos modos, mas, sim, de uma inteligibilidade, que seria a sucessão lógica (uma ordem), segundo a qual, em cada atributo, os modos produziriam uns aos outros. Espinosa apresenta este princípio de identidade causal, ou paralelismo, na Proposição 7 da parte II da Ética, ao afirmar que "a ordem e a conexão das ideias é a mesma que a ordem e a conexão das coisas". Com esta tese o filósofo explica que os atributos produzem seus respectivos modos de forma independente, mas a partir de um mesmo princípio causal, no qual cada modificação pode ser conhecida num duplo aspecto (corporal e mental); portanto, quando ocorre uma modificação corporal, sempre ocorre, paralelamente, uma modificação mental. Há um dualismo de propriedades e não de substâncias e há uma identidade causal que perpassa todos os atributos. Para Alquié, é compreensível que a substância seja o princípio de identidade de todas as ordens causais dos atributos, como Espinosa demonstra na proposição supracitada. Contudo, o erro de Brunschvicg residiria na identificação entre o princípio de identidade e o princípio de inteligibilidade. Esta identificação não é possível, pois o pensamento é apenas um atributo entre a multiplicidade dos atributos: não é porque toda modificação em qualquer atributo pode, pelo paralelismo, ser representada pelo pensamento, que o pensamento contém e envolve a realidade de todos os outros atributos. A unidade da substância não pode residir no atributo pensamento. A inteligibilidade é própria unicamente do atributo pensamento (no sentido de que só o pensamento é capaz de inteligir algo); a extensão, por exemplo, só pode ser declarada inteligível na medida em que é pensada (ALQUIÉ, 2003, pp.96-97).

Descartes já havia demonstrado que não podemos formar nenhuma ideia comum ao pensamento e à extensão, isto é, estes dois atributos são inteiramente distintos, de tal modo que, para um indivíduo conceber a ideia de pensamento não seria preciso conceber a ideia de extensão, e vice-versa, pois "há uma distinção radical, em Descartes, entre aquilo que é metafísico e aquilo que é físico" (ALQUIÉ, 2003, p.97). Alquié lembra que Brunschvicg tende a explicar toda a filosofia moderna pela geometria analítica, adotando como ponto fundamental a descoberta do meio que Descartes encontrou para exprimir em termos de pensamento puro aquilo que é intuição geométrica, por isso Brunschvicg teria dado tanto valor ao atributo pensamento de Espinosa. Contudo, diferentemente de Descartes, para Espinosa o atributo pensamento não pode ser igualado à consciência, pois o entendimento finito é apenas um modo causado pelo atributo pensamento.

Além de invalidar a interpretação de Brunschvicg acerca da identidade causal, Alquié acredita reforçar a impossibilidade desta segunda hipótese criticando a concepção do atributo pensamento apresentada pelo próprio Espinosa. Pois, ao afirmar que o atributo pensamento não pode ser o entendimento, mas a causa do entendimento, Espinosa teria apresentado um atributo que - diferentemente do atributo cartesiano, onde o pensamento seria definido pela consciência - está "afastado de tudo aquilo que chamamos pensamento" (ALQUIÉ, 2003, p.98), sendo, portanto, desconhecido e transcendente. Nas palavras de Alquié, "um pensamento não consciente é desconhecido e primeiro com relação ao entendimento. Ele é condição desse entendimento, sem lhe ser diretamente acessível" (ALQUIÉ, 2003, p.97).

OLIVEIRA, Marcio Francisco Teixeira de. Ferdinand Alquié contra o monismo de Espinosa. Griot : Revista de 
A terceira hipótese - esta sim, formulada por Alquié - insiste na afirmação da transcendência dos atributos; transcendência que seria sustentada pelo caráter divino da substância espinosista. Alquié acredita que Espinosa tenha elevado os atributos "a gêneros supremos" ao entender que não poderiam ser "graus menores de ser" (ALQUIÉ, 2003, p.98).

Apesar de Espinosa ter criticado Descartes por igualar atributo e modo, a intuição teológica e primeira da Ética apresentaria uma substância desconhecida, que não pode ser alcançada pela razão. $O$ comentador afirma que a filosofia de Descartes atribui o espaço aos corpos e o pensamento às almas, mas a obscuridade desta atribuição é limitada, pois "poderíamos saber a essência do corpo e da alma sem sermos levados, para além dessas essências, a uma coisa sobre a qual não teríamos a menor ideia" (ALQUIÉ, 2003, p.99). No caso de Espinosa, por outro lado, o pensamento e a extensão pertencem à mesma substância, estes atributos são o próprio Deus. Por isso, para Alquié, ao comparar a multiplicidade desconhecida dos atributos a "gêneros supremos", Espinosa teria igualado o Deus da Ética ao Deus escondido da Bíblia, ao Deus que revela que "é" sem revelar "o que é". Para confirmar esta interpretação, Alquié recorre ao trecho do Breve Tratado no qual Espinosa teria afirmado que os atributos desconhecidos nos dizem que eles são, sem nos dizer ao mesmo tempo o que eles são (ESPINOSA, 2012, p.52). Alquié lembra que o ser que diz que "é", sem dizer ao mesmo tempo isso que ele "é", é o Deus da Bíblia; é o Deus que diz, quando perguntado "Quem és tu?", "Eu sou aquele que sou" (BÍBLIA, Exodo, 3,14). A substância de Espinosa é comparada ao Deus da tradição hebraica por estar afastada, na sua incognoscibilidade, de toda natureza extensa que verdadeiramente aparece. Deste modo, o "Eu sou" figura a única coisa que o homem pode saber acerca desta substância (ALQUIÉ, 2003, p.98).

Alquié recorda que na demonstração da Proposição 19 da Parte I da Ética, Espinosa afirma que os atributos exprimem e explicam a substância:

\begin{abstract}
Além disso, por atributos de Deus deve-se compreender aquilo que (pela def. 4) exprime a essência da substância divina, isto é, aquilo que pertence à substância, que é precisamente, afirmo, o que esses atributos devem envolver. (SPINOZA, 2008, p. 43).
\end{abstract}

Sobre essa proposição, Alquié comenta que, em primeiro lugar, para exprimir Deus, o atributo deve ser semelhante a ele, isto é, o atributo deve ser autossuficiente, e isto não se pode negar dos atributos de Espinosa, portanto, podem exprimir a substância. Então, se perguntassem se é possível que os atributos de Espinosa exprimam a força, o poder, a eternidade e a infinidade da substância, a resposta deveria ser, também, afirmativa. No entanto, Alquié não concorda com a possibilidade de os atributos expressarem a unidade da substância, pois são múltiplos. Ele entende que a definição de substância única seja na realidade uma falta de definição, porque Espinosa recusa a ideia de que algum conceito possa formar o conceito de substância, pois, como vimos, Espinosa afirma na terceira definição do primeiro livro da Ética que por substância compreende o que "existe em si mesmo e por si mesmo é concebido, isto é, aquilo cujo conceito não exige o conceito de outra coisa do qual deva ser formado". Assim, já que não se pode formar o conceito de substância a partir de outro conceito, ela não pode ser definida. Portanto, o ser que fundaria o conhecimento seria ele

OLIVEIRA, Marcio Francisco Teixeira de. Ferdinand Alquié contra o monismo de Espinosa. Griot : Revista de Filosofia, Amargosa - BA, v.18, n.2, p.72-85, dezembro, 2018. 
mesmo incompreensível. Diferentemente do Espinosa tenta defender, a Natureza estaria acima da verdade. Nas palavras de Alquié:

O Deus de Espinosa é um Deus único. Espinosa também poderia dizer: Credo in unum Deum. Mas como esse Deus pode ser único? Não é evidente que a definição dessa substância única seja na realidade uma falta de definição? Porque ela recusa a ajuda de qualquer outro conceito para que o conceito de substância possa ser formado. A definição da substância exclui na realidade toda definição. Pois se eu não posso formar o conceito de substância a partir de nenhum outro conceito, isso quer dizer que eu não posso defini-la. Isto não seria reconhecer que o ser que funda todo o conhecimento é superior ao conhecimento? Não seria reconhecer que, qualquer que seja a infinidade do pensamento, a Natureza é superior à sua verdade? (...) Não podemos concordar agora que Espinosa coloca a Natureza acima da verdade na medida em que aquela é igualada a Deus? Considerados como atributos de uma substância única, os atributos nos conduzem a um Deus incompreensível, transcendente e oculto. (ALQUIÉ, 2003, pp.99-100).

Tendo inviabilizado as três hipóteses apresentadas acerca da unidade substancial, Alquié conclui que a unidade do Deus de Espinosa só seria concebível na medida em que o Deus de Espinosa não corresponda àquele que Espinosa quer apresentar, mas ao Deus desconhecido, transcendente e oculto da tradição. Com isso, Alquié acredita que a tese do monismo espinosista, isto é, a afirmação da existência de uma substância única constituída de infinitos atributos, seja incompatível com a estrutura argumentativa do primeiro livro da Ética, o que destruiria toda a filosofia de Espinosa.

Ferdinand Alquié também dedicou uma parte específica da obra Le Rationalisme de Spinoza para tratar do que ele intitula "o problema da unidade de Deus concebido como constituído de uma infinidade de atributos". Segundo o autor, “a consequência mais grave da definição de Deus como 'constituído” pelos atributos é que ela torna difícil, senão impossível, a concepção da unidade divina" (ALQUIÉ, 1998, p.120). Ele lembra que a Ética apresenta uma infinidade de atributos, dos quais os únicos que o ser humano pode conhecer são o pensamento e a extensão. De acordo com o autor, diante destes atributos realmente distintos, cujas ideias são diferentes e sem relação, a obra de Espinosa suscitaria a seguinte questão: "não tendo nada de comum, como Pensamento e Extensão, poderiam ser concebidos segundo a unidade e relacionados a uma única e mesma substância?" (ALQUIÉ, 1998, p.120). O comentador acredita que o problema da unidade de Deus parece irresolúvel, porque, para que esta unidade fizesse sentido, estes atributos diferentes só poderiam ser relacionados à substância única se ela fosse tomada como "desconhecida" e "transcendente", conclusão que o racionalismo de Espinosa rechaça, pois a Ética "exige que Deus não seja nem desconhecido nem transcendente" (ALQUIÉ, 1998, p.120).

Alquié se pergunta se o problema da unidade de Deus poderia ser comparado a um problema análogo enfrentado por Descartes, referente à unidade do homem. No caso de Descartes, a unidade entre a alma e o corpo só poderia ser claramente pensada a partir do momento em que o filósofo recorre a uma terceira "noção primitiva": na Carta a Regius, Descartes teria recorrido a um "ser por si", um ens per

OLIVEIRA, Marcio Francisco Teixeira de. Ferdinand Alquié contra o monismo de Espinosa. Griot : Revista de Filosofia, Amargosa - BA, v.18, n.2, p.72-85, dezembro, 2018. 
se, possuidor de uma alma e de um corpo. No caso de Espinosa, Alquié chama a atenção para o fato de que, na definição 6 da primeira parte da Ética, antes mesmo de dizer que Deus é uma substância, o holandês o nomeia como um "ser". Então o comentador pergunta: "Espinosa teria admitido que o ser divino possa realizar a unidade de várias substâncias tal como [em Descartes] o ser do homem realiza a unidade da alma e do corpo?" A resposta a esta pergunta Alquié considera como negativa, porque Descartes faz uso da evidência da experiência vivida da união em nós de uma alma e de um corpo, enquanto Espinosa se desfaz de todo e qualquer recurso à experiência interior, pois não apenas a consciência imediata é fonte de ilusões naturais (como a crença no livre arbítrio), mas ela leva o homem ao antropomorfismo e à ilusão. Além disso, Espinosa afirma no escólio da EIP15 que "aqueles que inventam que Deus, à semelhança do homem, é constituído de corpo e mente (...) se desviam do verdadeiro conhecimento de Deus" (SPINOZA, 2008, p. $31)$.

Alquié afirma que é a partir da Proposição 9 da primeira parte da Ética que Espinosa sustenta, pela Definição 4, sua doutrina da unidade do Deus composto (composé) de diversos atributos (ALQUIÉ, 1998, p.121); a proposição afirma: "quanto mais realidade ou ser uma coisa tem, tanto mais atributos lhe competem". Para o comentador, o uso da Definição 4 é causa de uma grande perplexidade, porque ele não entende como Espinosa foi capaz de fazer com que uma definição cartesiana e relativa aos atributos pensamento e extensão, pertencentes a substâncias diversas, se tornasse habilitada a conduzir a possibilidade desses atributos diferentes existirem em um único ser.

Alquié sustenta que a Proposição 9 traz consigo muitas dificuldades: 1- esta proposição supõe que uma coisa qualquer possa receber mais ou menos atributos, mas ignora que os atributos, não sendo propriedades, são eles mesmos "coisas"; 2 Alquié reclama que somente Deus, e não qualquer coisa, pode ser dito como possuidor de atributos; 3 - diz também que, se para Espinosa o número é um fruto ilusório da imaginação (isso é dito, por exemplo, na Carta 12, já citada acima) os atributos não poderiam ser contados; 4 - cita a carta a Schuller de 29 de julho de 1675, na qual Espinosa teria rejeitado a hipótese de que pudessem existir "seres tendo três, quatro ou mais atributos"; 5 - ainda sobre a questão do número, ele lembra que, para que se possa enumerar, é preciso primeiro levar as coisas ao mesmo gênero, de modo que "todas as maçãs sendo [consideradas] maçãs, eu posso claramente falar de uma maçã ou de várias maçãs" (ALQUIÉ, 1998, p.122), mas os atributos, sendo concebidos cada um por si - isto é, sem o conceito de nenhuma outra coisa - não podem cair sob um mesmo gênero. Após apontar rapidamente estas dificuldades, Alquié pergunta: se não é no sentido aritmético que se deve falar da unidade de Deus ou da multiplicidade de seus atributos (onde cada um possui uma essência própria), "como compreender que se trata aqui de uma questão de plura atributa?". Como interpretar, sem ter de recorrer ao número, o Corolário I da Proposição 14, segundo o qual "Deus é único (unicum)" e "não existe, na natureza das coisas, senão uma única substância"?

Descartes também usa o princípio dos graus de ser ao afirmar que "existem diversos graus de realidade ou de entidade, pois a substância tem mais realidade que o acidente ou o modo, e a substância infinita mais que a finita" (DESCARTES, 
1852, p.592); em Descartes, este princípio serve para classificar todas as coisas indo do nada, que não tem nenhuma propriedade positiva, até Deus, que possui todas as propriedades positivas. Para Alquié, um cartesiano pode atribuir diversas propriedades a uma substância; mas ele não entende como um espinosista poderia, na medida em que os atributos são substâncias, fazer com que "substâncias múltiplas pudessem 'constituir' uma outra substância. Um conjunto de substâncias só pode, aos nossos olhos, constituir um agregado de substâncias, não uma substância nova possuindo uma verdadeira unidade" (ALQUIÉ, 1998, p.123). Para Alquié, se cada atributo, concebido por si, é uma substância, não está claro como dois atributos poderiam constituir uma substância única; isto só estaria claro se o atributo conservasse seu sentido de "propriedade".

Não conseguindo conceber como os atributos podem constituir a essência de uma substância que seja única, Alquié conclui que a unidade do Deus de Espinosa só seria possível na medida em que este Deus não fosse aquele que o filósofo holandês desejava apresentar. Mas, se Alquié estava certo, como pode ser possível que até hoje muitos filósofos aceitem como válida a construção da tese do monismo? Outros grandes comentadores se insurgiram contra as acusações que procuram invalidar o monismo, tendo desenvolvido respostas muito interessantes e coerentes. É o caso, por exemplo, dos trabalhos de Martial Gueroult em, Dieu I, e de Gilles Deleuze, em Spinoza et le problème de l'expression (traduzido recentemente para o português), cuja leitura é recomendada aos interessados pela temática. 


\section{Referências}

ALQUIÉ, Ferdinand. Le rationalisme de Spinoza, 3. ed. Paris, PUF, 1998.

Nature et vérité dans la philosophie de Spinoza. In: Leçons sur Spinoza. Paris:

Éditions de la Table Redonde, 2003.

BÍBLIA. A.T. Êxodo. Português. Bíblia Sagrada. 26. ed. São Paulo: Ed. Ave Maria, 1982.

DELEUZE, Gilles. Spinoza et la méthode générale de M. Gueroult. Revue de Métaphysique et de Morale, 74e Année, No. 4 (Octobre-Décembre 1969), pp.426-437. . Spinoza et le problème de l'expression. Paris: Les Editions de Minuit, 1968.

DESCARTES, René. Discurso do método, As paixões da alma, Meditações Metafísicas, Objeções e respostas, Cartas. Col. Os Pensadores. São Paulo, Abril Cultural, 1973.

.Oeuvres de Descartes. 12 vols. Ed. de Ch. Adam \& P. Tannery. Paris, Vrin/Centre National du Livre, 1996. (AT)

Oeuvres philosophiques de Descartes: publibées daprès les textes originaux par

L. Aimé-Martin. Paris: Panthéon littéraire, 1852.

- Princípios da filosofia. Tradução coordenada por Guido de Almeida (Coleção Philosophia Analytica). Rio de Janeiro: Editora UFRJ, 2002.

ESPINOSA, Baruch de. Breve tratado de Deus, do homem e do seu bem-estar. Tradução de Emanuel da Rocha Fragoso e Luís César Oliva. Belo Horizonte: Autêntica, 2012.

Tratado da correção do intelecto. São Paulo: Nova Cultural, 1973. (Os Pensadores).

GLEIZER, Marcos André. Espinosa \& a afetividade humana. Rio de Janeiro: Zahar Ed., 2005.

2014.

. Lições introdutórias à Ética de Espinosa. Rio de Janeiro: Ed. Viaveritas,

GUEROULT, Martial. Spinoza, I, Dieu. Paris: Aubier-Montaigne, 1968.

MACHADO, Roberto. Deleuze e a filosofia. Rio de Janeiro: Graal, 1990.

SPINOZA, Benedictus de. Ética. Trad. Tomaz Tadeu. Belo Horizonte: Autêntica editora, 2008.

Obra Completa II: Correspondência completa e vida. Guinsburg, J;

Cunha, N.; Romano, R. (orgs). São Paulo: Perspectiva, 2014.

- Tratado da reforma do entendimento. Trad. Lívio Teixeira. São Paulo:

Martins Fontes, 2004.

Autor(a) para correspondência: Marcio Francisco Teixeira de Oliveira, Universidade do Estado do Rio de Janeiro, Instituto de Filosofia e Ciências Sociais, Largo São Francisco de Paula, 1 - Centro, CEP 20051-070, Rio de Janeiro - RJ, Brasil. franciscomarciorj@gmail.com 